\title{
Trace Analysis of Carbazole in Commercial Diesel by using Adsorption on Activated Biochar from Rice Husk Pyrolysis
}

\author{
Gabriela P. S. Maciel ${ }^{1}$, Eliane Lazzari ${ }^{2}$, Thiago Bjerk ${ }^{3}$, Samir M. Ahmad ${ }^{4}$, \\ Ana P. Carvalho ${ }^{5}$, José M. F. Nogueira ${ }^{6}$, Elina B. Caramão \\ ${ }^{1}$ Departamento Interdisciplinar, Universidade Federal do Rio Grande do Sul - Campus Litoral Norte, Tramandaí, RS, Brazil. \\ ${ }^{2,7}$ Instituto de Química, Universidade Federal do Rio Grande do Sul, Porto Alegre, RS, Brazil \\ ${ }^{4,5,6}$ Centro de Química e Bioquímica, Faculdade de Ciências, Universidade de Lisboa, Campo Grande Ed. C8, 1749-016 \\ Lisboa, Portugal \\ ${ }^{7}$ Instituto Nacional de Ciência e Tecnologia - Energia e Meio Ambiente, Salvador,BA, Brazil \\ ${ }^{3,7}$ Departamento de Biotecnologia Industrial, Universidade Tiradentes, Aracaju, SE, Brazil
}

\begin{abstract}
The valorization of rice husk biochar obtained by pyrolysis was studied by production high quality activated carbon. Activated carbon (AC) chemically treated by $\mathrm{K}_{2} \mathrm{CO}_{3}$, was used as sorbent phase in bar adsorptive microextraction followed by comprehensive two-dimensional gas chromatography coupled to a quadrupole mass spectrometer analysis $(B A \mu E / G C \times G C-q M S)$ for trace analysis of carbazole in commercial diesel. The prepared AC was characterized by $\mathrm{N}_{2}$ adsorption, SEM-EDS and $\mathrm{pH} \mathrm{HZC}_{\mathrm{PZ}}$. Assays of nitrogen adsorption isotherm demonstrated that the AC presented microporosity and the Density Functional Theory Calculation was applied to obtain information concerning the micropore size distribution. The BET surface area and total pore volume were $1850 \mathrm{~m}^{2} \mathrm{~g}^{-1}$ and $0.83 \mathrm{~cm}^{3} \mathrm{~g}^{-1}$, respectively. AC from rice huskpyrolysis $(R H)$ showed an acceptable adsorption capacity for Carbazole in diesel matrices allowed us to obtain average recoveries of $91.0 \%$ and convenient analytical parameters. From the data obtained, the proposed methodology proved to be a suitable sorption-based static microextraction alternative for monitoring trace levels of carbazole in commercial diesel.
\end{abstract}

Keywords - Rice husk pyrolysis, Activated carbon, Chemical activation, Bar adsorptive microextraction, BA $\mu E / G C \times G C$ qMS, Nitrogen compounds, Diesel.

\section{INTRODUCTION}

In the last year, there was a growing interest in using low-cost and abundantly available waste materials as precursors of carbon materials. Actually, any carbonaceous material with high carbon content can be used as raw material for the preparation of activated carbons (ACs) [1]. This is the case of $t$ agricultural solid wastes [2], such as, cotton stalk [3,4], tobacco stem [5], rice husk [6], cork [7], bamboo [8], waste tea [9, 10], coconut shell [11], oil palm fiber [12], durian shell [13], wood [14], sisal [15] and many others.

In South Brazil, rice processing is an important agro-industrial sector, giving rise to large amounts of rice husk (about 2.5 million metric tons per year) produced as agricultural waste. Fast pyrolysis is an interesting option for the reducing the environmental impact and to valorize rice husk, as shown in a previous study [16]. The production of AC from rice husk is achieved through chemical or physical activation [17].

Chemical activation is a widely used method to obtain $\mathrm{AC}$ with a very large surface area and great micropore volume and is usually performed using $\mathrm{NaOH} / \mathrm{KOH}$ [18-21], $\mathrm{H}_{3} \mathrm{PO}_{4}$ [22] or $\mathrm{ZnCl}_{2}[20,23] . \mathrm{K}_{2} \mathrm{CO}_{3}$ is an alternative to $\mathrm{KOH}$ with the advantage that carbonate mediated activation is less extensive, as well as being a more environmental friendly activating agent when compared to the most commonly reported chemical activating agents above mentioned. In fact, $\mathrm{K}_{2} \mathrm{CO}_{3}$ is nontoxic (can be used as food additives), is easy removed by water washing, has weak corrosion thus allowing good operating conditions. The uses of $\mathrm{K} 2 \mathrm{CO} 3$ as activating agent have been reported by several authors [3, 7, 15, 24-29] resulting in the preparation of ACs with high surface area [13] and developed microporosity.

ACs exhibit excellent adsorption performance in the process of nitrogen and sulfur removal from many different matrices and are the most used adsorbents [30,31]. Adsorptive denitrogenation and desulphurization is considered promising methodology when compared with the conventional hydrodenitrogenation and hydrodesulphurization process, because it can be run at ambient conditions without using hydrogen and catalysts [32]. The importance of denitrogenation process results from the fact that although nitrogen compounds are present at low concentrations, they play an important role in the quality of oil products. Non-basic nitrogen compounds (e.g. carbazole) account for about $70 \%$ of the load of nitrogen compounds in the atmospheric gas oil, being a major nitrogen component of diesel fuel [33]. 
Since nitrogen compounds are more difficult to be eliminated in hydroprocessing, several methods for their isolation are described in the literature $[34,35]$. However, many procedures use separation with open column liquid chromatography, which implies the use of large volumes of solvent, costly adsorbent materials as stationary phases, and long separation times.

In the last decades, new microextraction techniques have emerged, namely solid-phase microextraction and stir bar sorptive extraction, since they use negligible amount of solvent, low sample volume and simplified approach [36]. However, these techniques use a small number of polymeric materials (e.g., polydimethylsiloxane) as sorbents and the coating with ACs is

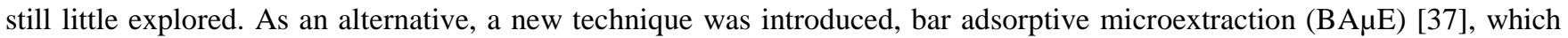
offers the operator the possibility to choose the most convenient sorbent phase (polymers or ACs), according to the chemical characteristics of the target analytes [36].

In recent years, researchers have explored environmental friendly and low cost materials as precursors to prepare ACs that presented high apparent specific surface areas and good performance when tested as adsorbents for nitrogen compounds [32, 38].Examples of these materials are biochars from the pyrolysis or combustion of biomasses. The possibility of producing carbon materials with high specific surface areas and micropore volume allied with a considerable surface reactivity make these materials adequate for a great number of applications. According to the authors' knowledge, AC prepared from rice husk pyrolys is using $\mathrm{K}_{2} \mathrm{CO}_{3}$ activating agent has not still investigated in the analysis of the nitrogen compounds of diesel samples until now.

In this study, rice husk biochar (obtained from the pyrolysis of rice husk) was subjected to a chemical treatment with $\mathrm{K}_{2} \mathrm{CO}_{3}$ and the chemical characterization of the prepared $\mathrm{AC}$ was performed. The purpose of this research is to evaluate the microextraction feasibility of traces of nitrogen compounds from diesel using BA $\mathrm{BE}$ coated with novel AC sorbents following by comprehensive two-dimensional gas chromatography coupled to a quadruple mass spectrometer (GC $\times \mathrm{GC}$ qMS) analysis. The proposed methodology was applied, for the first time, in the analysis of carbazoles in commercial diesel samples and the analytical performance was evaluated in terms of accuracy, precision, linearity and detection limits.

\section{MATERIAL AND METHODS}

\subsection{Materials and chemical reagents}

All reagents used in this work were of analytical grade. HPLC-grade methanol (MeOH, 99.9\%) and acetonitrile (ACN, 99.9\%) were purchased from Panreac (Spain).Dichloromethane (DCM, 99\%) was provided by Vetec (Brazil). Reference standards carbazole and acenaphthene D-10 (internal standard), as well as nonane, tetradecane and hexadecane, were used to prepare the standard solutions and for sample dilution, which were provided by Sigma-Aldrich (Seelze, Germany), with purity higher than $97 \%$. $\mathrm{K}_{2} \mathrm{CO}_{3}(99.6 \%)$ used as activating agent was supplied by Prolabo, VWR Chemicals. Rice husk was gathered from a farm in Rio Grande do Sul, south of Brazil. All the biomass material was crushed by a high-speed rotary cutting mill, sieved to limit the particle size (40-60 mesh). Commercial diesel fuel was obtained from a local gas station in Lisbon, Portugal.

\subsection{Biomass pyrolysis and preparation of $\mathrm{AC}$}

The pyrolysis procedure of rice husk $(\mathrm{RH})$ was performed in a stainless steel vertical oven containing a quartz reactor; more details can be obtained from other study [39]. After some optimization experiments, $3 \mathrm{~g}$ of rice husk were heated under nitrogen atmosphere, $\mathrm{N}_{2}$ flow of $1 \mathrm{~L} \mathrm{~min}^{-1}$, at $650{ }^{\circ} \mathrm{C}$ using a heating rate of $100{ }^{\circ} \mathrm{C} \mathrm{min}^{-1}$. The reactor was maintained at 650 ${ }^{\circ} \mathrm{C}$ for $5 \mathrm{~min}$ at the end of the process.

To prepare the active carbon, in the following designated as AC-RH, biochar was mixed with $\mathrm{K}_{2} \mathrm{CO}_{3}$ in 1:3 weight ratio of char: $\mathrm{K}_{2} \mathrm{CO}_{3}$. The mixture was activated in a horizontal furnace (Thermolyne mod. 21100), under $\mathrm{N}_{2}$ flow $\left(5 \mathrm{mLs}^{-1}\right)$. The temperature was raised $\left(10^{\circ} \mathrm{C} \mathrm{min}^{-1}\right)$ up to the activation temperature $\left(800^{\circ} \mathrm{C}\right)$ that what kept for $2 \mathrm{~h}$. After cooling, under $\mathrm{N}_{2}$ flow, the sample was washed with distilled water up to $\mathrm{pH} 7$ and dried at $100^{\circ} \mathrm{C}$.

\subsection{Characterization of AC}

Textural characterization was performed using $\mathrm{N}_{2}$ adsorption-desorption isotherms at $-196{ }^{\circ} \mathrm{C}$, using a Tristar $\mathrm{Kr} 3020$ Micromeritics equipment. The samples were previously degassed at $120^{\circ} \mathrm{C}$ under vacuum, for $12 \mathrm{~h}$. The specific surface area was determined by BET (Brunauer, Emmett and Teller) multipoint technique. The pore size distribution in the micropore range was obtained using the Horvàth-Kawazoe (HK) method [40]. Meanwhile, the whole pore size distribution was computed by the DFT (Density Functional Theory) method [41]. 
In order to observe the morphological textures onto the char and $\mathrm{AC}$, these samples were examined by using a highresolution scanning electron microscopy equipped with an energy-dispersive spectrometer (SEM-EDS). The SEM-EDS analysis was carried out with Zeiss (EVO MA10 model) which was operated at $15 \mathrm{kV}$ accelerating potential. Prior to the SEM-EDS observation, samples were previously coated with gold.

Further characterization was performed by means of the point of zero charge $\left(\mathrm{pH}_{\mathrm{PZC}}\right)$, of the sample by reverse mass titration, following the method procedure described in Mestre et al [42].

\subsection{Preparation of $\mathrm{BA} \mu \mathrm{E}$ devices}

For the bar configuration, the BA $\mu \mathrm{E}$ devices were prepared by coating polyethylene hollow cylindrical tubes (7.5 mm in length and $3.0 \mathrm{~mm}$ in diameter) with adhesive films, which was coated with the powdered AC (approximately $2 \mathrm{mg}$ ). Before use, the bars were previously cleaned through ultrasonic treatment using heptane as solvent. The detailed description of devices manufacturing can be checked at other works [37, 43].In real sample assay, the standard addition methodology (SAM) was applied, followed by the same procedure employed for the validation experiments. The mixture of nonane, tetradecane and hexadecane was denominated synthetic diesel. $10 \mathrm{~mL}$ of commercial diesel sample diluted 5 times with synthetic diesel spiked with carbazole standard, using three levels of concentration $\left(0.100,0.025,0.0125 \mathrm{mg} \mathrm{L}^{-1}\right)$, and a $\mu$ extraction bar device previously coated with AC were introduced into glass flasks. The glass flasks were placed in a multipoint agitation plate (Variomag) with agitation speed of $750 \mathrm{rpm}$ at room temperature for $1 \mathrm{~h}$. The assays were performed in triplicate. For back-extraction, the $\mu$-extraction bar device was removed from the samples with clean tweezers and placed into a $1.5 \mathrm{~mL}$ vial with a glass insert containing $200 \mu \mathrm{L}$ of $\mathrm{MeOH} / \mathrm{ACN}(1: 1 \mathrm{v} / \mathrm{v})$, ensuring their total immersion prior to ultrasonic treatment at room temperature using a desorption time of $30 \mathrm{~min}$. After back-extraction, the AC-RH bar was removed with clean tweezers and the stripping solvent was evaporated until dryness under a gentle stream of purified nitrogen $(99.9 \%)$, followed by reconstitution with $200 \mu \mathrm{L}$ of dichloromethane. The vial was then sealed and placed in the auto sampler for $\mathrm{GC} \times \mathrm{GC} / \mathrm{qMS}$ analysis. Blank assays were also performed using the procedure above described without spiking.

\subsection{Instrumentation settings}

The GC $\times$ GC-qMS system consisted of a chromatograph Shimadzu QP2010 Ultra (Shimadzu, Japan) equipped with a cryogenic modulatorZX1-GC $\times \mathrm{GC}(\mathrm{ZOEX}$ Corporation, Houston, USA). This modulator utilizes liquid nitrogen (Linde Gases, Brazil) for the cold jet and gaseous nitrogen for the hot jet. A non-polar column DB-5 (5\% of phenyl groups in a methyl silicon stationary phase, with $60 \mathrm{~m} \times 0.25 \mathrm{~mm}$ i.d. $\times 0.25 \mu \mathrm{m}$ film thicknesses, Ohio Valley Specialty Company, USA) was used in the first dimension. A more polar column DB-17 (50\% of phenyl groups in a methyl silicon stationary phase, with $2.15 \mathrm{~m} \times 0.18 \mathrm{~mm} \times 0.18 \mu \mathrm{m}$, J\&W Scientific, Agilent Technologies, USA), was used in the second dimension. Different temperature programs, modulation periods and column flow rates were tested. A conventional split/splitless injector was used at $280{ }^{\circ} \mathrm{C}$, with an injection volume of $1.0 \mu \mathrm{L}$ in splitless mode. The GC program began at an initial temperature of $70{ }^{\circ} \mathrm{C}$ and was held at this temperature for $2 \mathrm{~min}$, then the oven was heated to $200{ }^{\circ} \mathrm{C}$ at $3{ }^{\circ} \mathrm{C}$ min ${ }^{-1}$ and then to $280^{\circ} \mathrm{C}$ at $5^{\circ} \mathrm{Cmin}^{-1}$ and held for $3 \mathrm{~min}$. The carrier gas was helium under a constant flow rate of $0.86 \mathrm{~mL} \mathrm{~min}^{-1}$. The interface and ion source were maintained at $280{ }^{\circ} \mathrm{C}$, and the total flow rate was $21.1 \mathrm{mLmin}^{-1}$. The fast quadrupole MS conditions were: energy of $0.83 \mathrm{kV}$ and mass scan range from 45 to $300 \mathrm{Da}$, corresponding to a frequency of $73.3 \mathrm{~Hz}$. A modulation period of $4 \mathrm{~s}$ and the hot jet time was set to $300 \mathrm{~ms}$. Data processing by GC $\times \mathrm{GC}$-qMS was performed using the GC Image 2.2b1 software (ZOEX Corporation), and the NIST-05 library was used to identify carbazole with a similarity of at least $90 \%$, which was confirmed by the retention time of the standard.

\subsection{Recovery assays and method validation}

For identification purposes, pure standards samples were injected for comparing the retention parameters and peak purity with the MS spectral reference database. For recovery calculations, peak volumes on the tridimensional diagram obtained from each assay were compared with the peak volumes of standard control used for spiking. For quantification purposes on real matrices, calibration plots using the SAM approach were performed. The present methodology was validated according to international guidelines for linearity, limits of detection (LOD) and quantification (LOQ), as well as intra- and inter-day precision. 


\section{RESULTS AND DISCUSSION}

\section{1 $\quad \mathrm{N}_{2}$ adsorption isotherm and pore size distribution of $\mathrm{AC}$}

The BET surface area $\left(0<p / p^{0}<1\right)$ increased from $223 \mathrm{~m}^{2} \mathrm{~g}^{-1}$ to $1850 \mathrm{~m}^{2} \mathrm{~g}^{-1}$ after the activation. According to the literature, for example the study of Adinata et al. [24] the specific surface areas of $\mathrm{K}_{2} \mathrm{CO}_{3} \mathrm{ACs}$ increases with the carbonization temperature up to $800{ }^{\circ} \mathrm{C}$ and slightly decrease when higher temperatures are applied. Therefore, it was deduced that $\mathrm{K}_{2} \mathrm{CO}_{3}$ was effective as activation reagent below $800{ }^{\circ} \mathrm{C}$. As reported in the literature alkali metal atoms are removed from the intercalated system at higher temperature; therefore the surface area and pore diameter may increase [1].

The $\mathrm{N}_{2}$ adsorption and desorption isotherms obtained for the biochar and AC-RH samples were shown in Figure1, in accordance with the International Union of Pure and Applied Chemistry (IUPAC) [44] classification the isotherms resembles a combination of type I and type IV isotherms, displaying a marked characteristic microporous associated with a mesoporous structure, as demonstrated by its initial adsorption and the plateau region at higher relative pressure. After a sharp increase up to 0.1 of relative pressure, the isotherm showed a slow increment in the further adsorption at higher pressure.

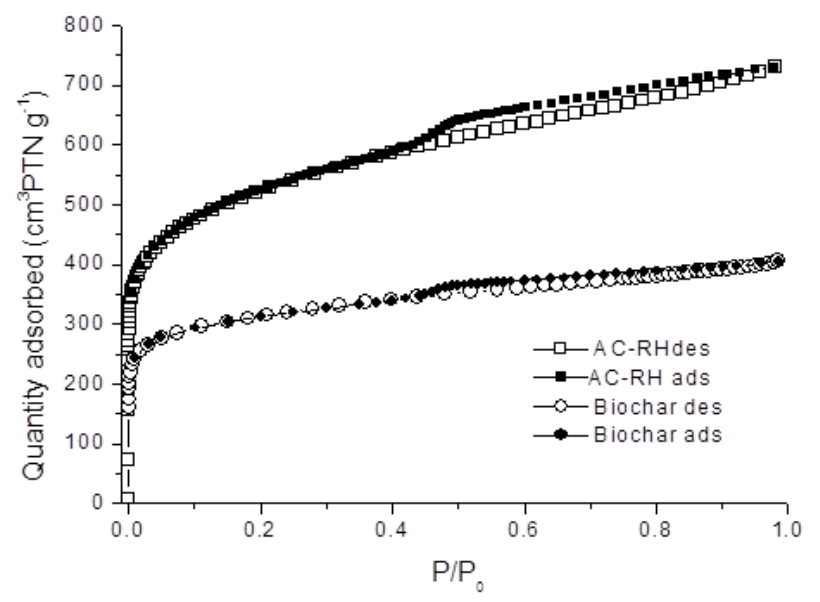

\section{FIGURE 1. NITROGEN ADSORPTION-DESORPTION ISOTHERM SAT $-196^{\circ} \mathrm{C}$ ON THE MENTIONED SAMPLES.} CLOSED SYMBOLS REPRESENT DESORPTION POINTS.

The corresponding pore size distribution for the AC according to the HK method was shown in Figure 2a, in which micropores less than $1.0 \mathrm{~nm}$ were presented. Figure $2 \mathrm{a}$ exhibited a narrow micropore distribution at the range of 0.50-0.75 $\mathrm{nm}$ and showed that the vast majority of micropores were ultra micropores (pore widths $<0.7 \mathrm{~nm}$ ), which represents an important contribution for the overall porosity of this carbon material. The whole pore size distribution was calculated by Density Functional Theory (DFT) method as illustrated in Figure2b. The pore size distribution curve suggested a predominant micropore owing to the sharp increase of pore size distribution curve to pore diameter less than $2.0 \mathrm{~nm}$, in good agreement with the HK method results.

(a)

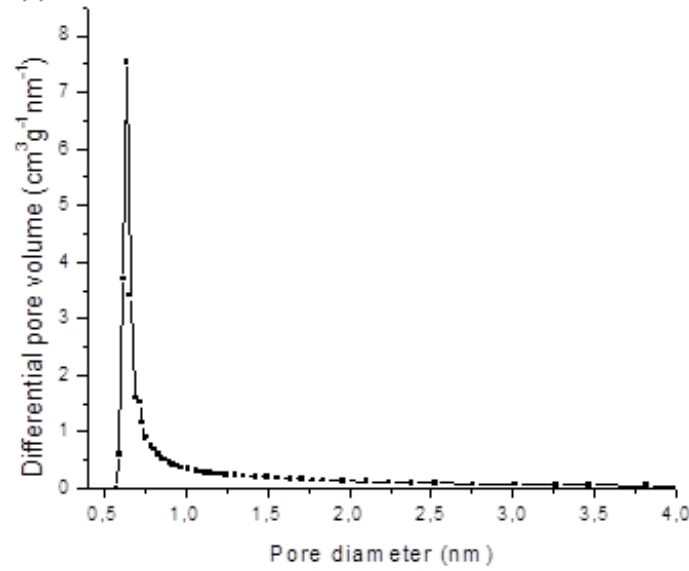

(b)

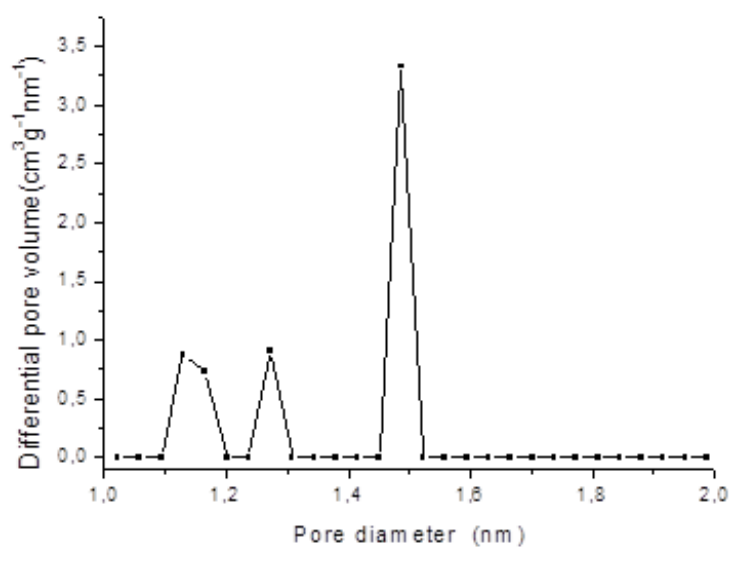

FIGURE 2. MICROPORE SIZE DISTRIBUTION OF AC-RH BY HK METHOD (a) AND PORE SIZE DISTRIBUTION OF AC-RH BY DFT METHOD (b). 


\subsection{Visual inspection of SEM images}

Scanning electron microscopy (SEM-EDS) technique was employed to observe the surface physical morphology of samples. Figure 3 depicts the SEM images of the char and AC, respectively. A significant difference of the surface topography between biochar and AC-RC was observed. The image of the biochar showed a smooth surface with slit like cracks and voids, relatively organized on the surface (Figure 3a). The image of the biochar sample in another region (Figure 3b) demonstrates porous less regular, whereas remarkably regular and homogenous surface morphology are observed for the AC sample (Figure 3c). Nevertheless, it could be seen from the micrographs that the external surface of the chemically AC-RH was full of cavities. A gradual improvement is observed on the surface morphology with the chemical activation. The surface of the AC is smoother and more porous structured than that of the biochar, and illustrated significant changes in the total surface area as reported in the previous sections. As seen in the images (Figure 3d), crater like macropores formed during the reactions between the biochar and $\mathrm{K}_{2} \mathrm{CO}_{3}$. Examination of the image (Figure 3d) clearly reflects that the holes on the particles are in macropore size and have various geometry but majority of them in more distorted circular shape. Those pores resulted from the reactions between carbon matrix and the chemical reagent during activation. In addition, after $\mathrm{K}_{2} \mathrm{CO}_{3}$ activation, the $\mathrm{AC}$ is washed, these salts formed in the activation can be leached out by water to form micropores within the carbon matrix, vide Figure $3 e$ and $f[45,46]$.
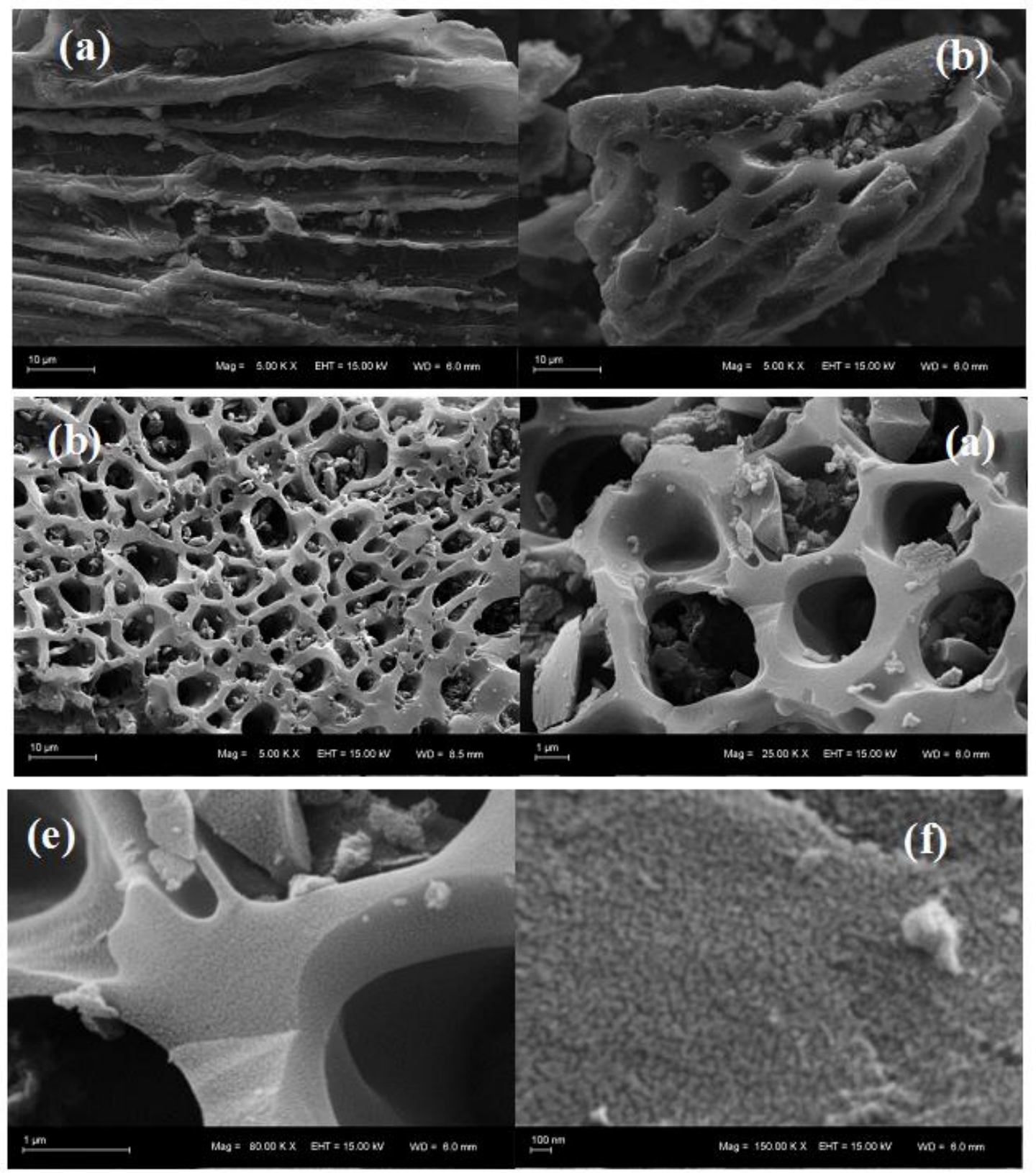

FigURE 3. SEM MICROGRAPHS OF (a, b) THE BIOCHAR AND (c, d,e, f) AC-RH. 
The SEM-EDS studies shed more light on leaching results. These analyses also indicated that silicates would be the dominating compounds in the biochar. This was expected for the biomasses, given the high content of this element in RH[47]. The rice husk silica was found in large shell-like inclusions in the biochar consisted in a carbon structure coated of practically pure silica particles. Skrifvars et al. [48] defined as "skeleton" that pure silica layer. As shown in Figure 4a there was a shell-like (Point 1) and the silica content obtained by EDS around Point 1 was 12.4 wt $\%$, which was righter than that around Point $2(2.0 \mathrm{wt} \%)$.However, in AC the silica was found fairly evenly distributed around the carbon inclusions. It can be clearly seen with the EDS map presented in Figure 5. In addition to C, O and Si, a minimal amount of others elements were found in both samples. The detailed elemental spectra data at biochar (Point 1 and 2) and A Care shown in Table 1.
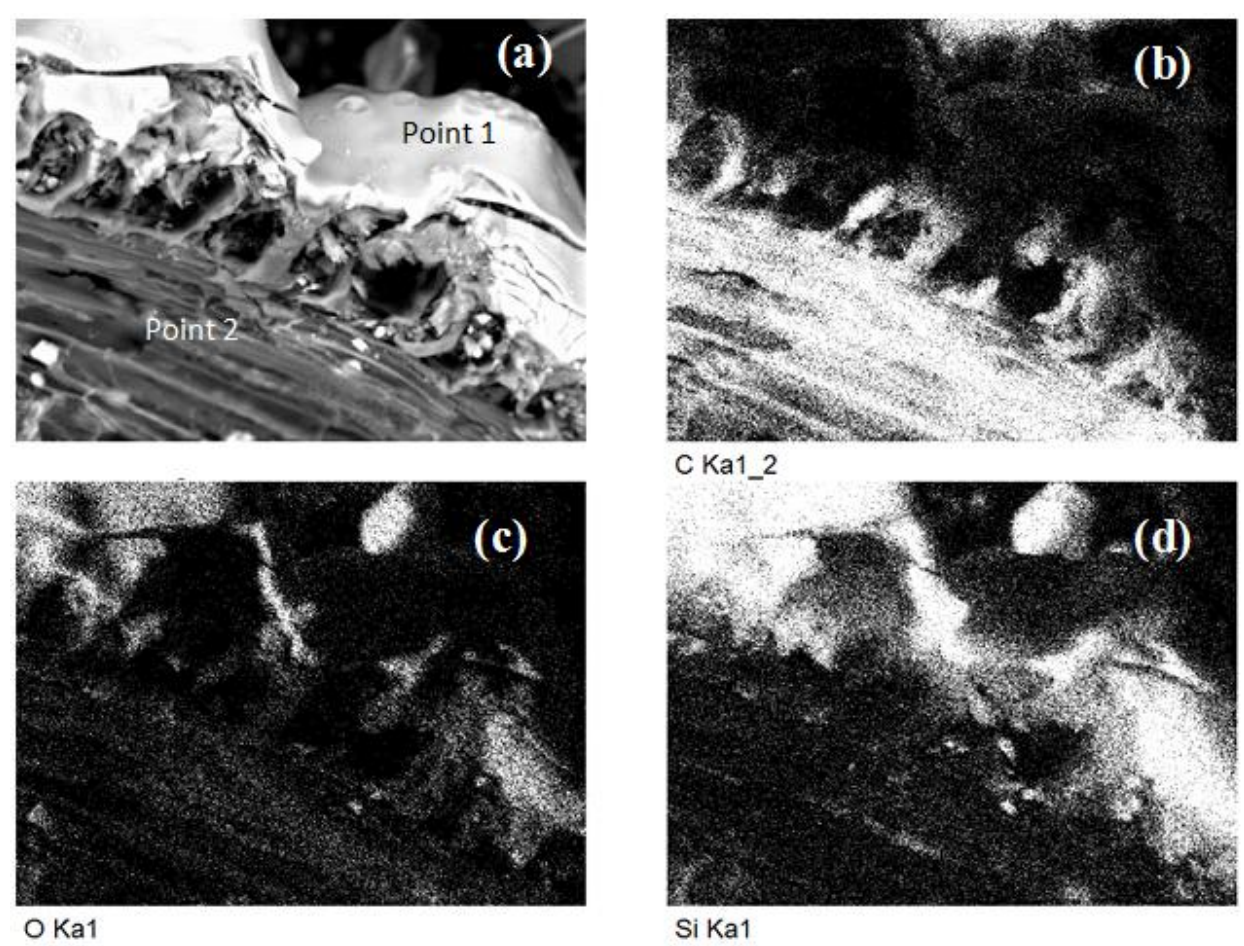

Si Ka1

FIGURE 4. SEM-EDS IMAGES OF THE BIOCHAR (a) AND MAPPING OF (b) CARBON, (c) OXYGEN AND (d) SILICON.
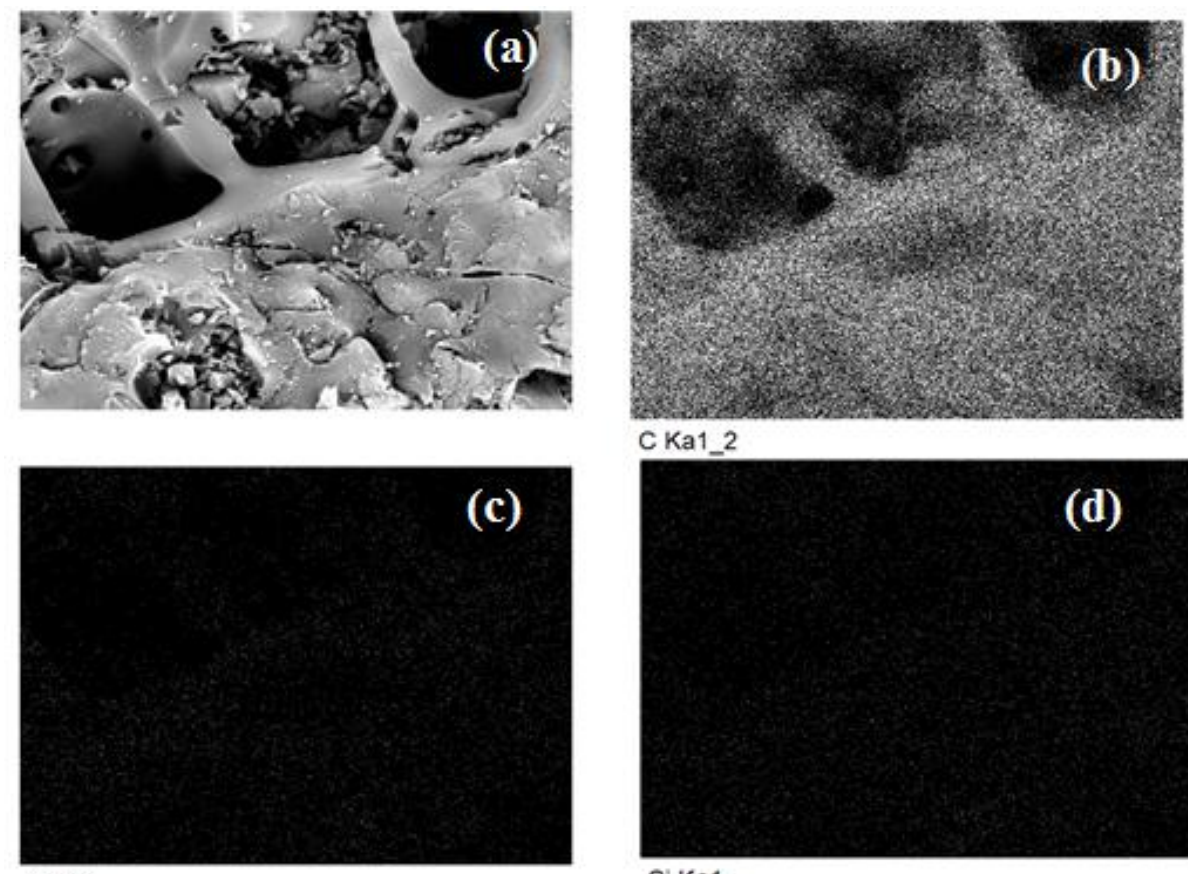

C Ka1_2

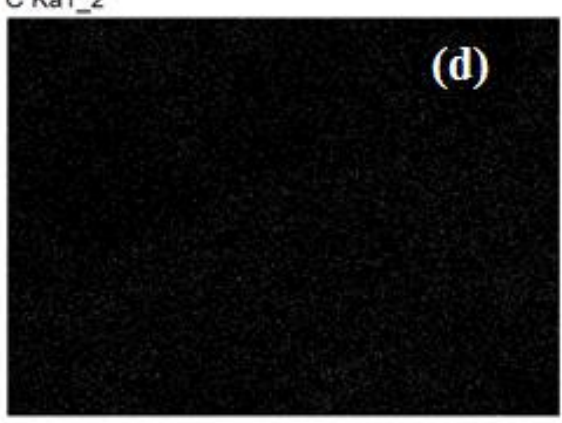

O Ka1

Si Ka1

FIGURE 5. SEM-EDS IMAGES OF THE AC-RH (a) AND MAPPING OF CARBON (b). 


\section{TABLE 1}

\section{CHEMICAL COMPOSITION OF THE ACTIVATED CARBON AND CHAR (POINT 1 AND 2), AS DETERMINED BY EDS} ANALYSIS

\begin{tabular}{|c|c|c|c|c|c|c|c|}
\hline Sample & \multicolumn{7}{|c|}{ Average mass percentage \% } \\
\hline & C & O & Si & Mg & P & Ca & K \\
\hline AC & 91.96 & 7.52 & 0.40 & - & - & - & 0.05 \\
\hline Char (Point 1) & 67.54 & 18.70 & 12.37 & 0.02 & 0.05 & 0.29 & 1.03 \\
\hline Char (Point 2) & 86.25 & 11.08 & 2.00 & 0.03 & 0.04 & 0.03 & 0.42 \\
\hline
\end{tabular}

\subsection{Point of zero charge analysis of $\mathrm{AC}$ and char}

The surface acidity and basicity is an important criterion describing the surface chemistry of the carbon adsorbents. The $\mathrm{pH}_{\mathrm{PZC}}$, defined as the $\mathrm{pH}$ at which the adsorbent surface has net electrical neutrality, in other words, the point that the net charge of adsorbent is zero. Regarding the surface chemistry, the $\mathrm{pH}_{\mathrm{PZC}}$ value revealed that the as-received biochar has basic nature $\left(\mathrm{pH}_{\mathrm{PZC}} 9.0\right)$. The chemical activation process led to a sample with an acidic surface since the $\mathrm{pH}$ at the point of zero charge decreased more than $3 \mathrm{pH}$ units. The $\mathrm{pH}_{\mathrm{PZC}}$ of $\mathrm{AC}-\mathrm{RH}$ was found to be as 5.6.

\section{CONSIDERATIONS ON TRACE ANALYSIS OF NITROGEN COMPOUNDS IN DIESEL}

There is a general consensus on the difficulty of removing nitrogen compounds in diesel samples. The very low concentrations of nitrogen compounds in commercial diesel and the presence of huge hydrocarbon matrix and sulfur/oxygencontaining compounds interferes with the analysis. To overcome the problems of having a low concentration of nitrogen compounds in diesel, it was vital perform a previous enrichment step. Several approaches have been proposed for the speciation of nitrogen in diesel, and a lot of methods for their isolation are reported in the literature [34, 35, 49-52].However, these methods generally comprise a combination of several analytical steps and use different laborious techniques, such as liquid-liquid extraction [51, 52], solid-phase extraction[49, 50], ion-exchange chromatography [34, 35], and others [53]to concentrate and isolate the nitrogen compounds in diesel. The liquid-liquid extraction methods are complex and may cause the significant loss particular types of nitrogen compounds, such as the more neutral species, due to their lower extraction selectivity. Most of these proposed techniques involve separation by open column chromatography [34, 35, 49]and though useful, use large volumes of solvents and many expensive materials and demand long separation times. Furthermore, these separation processes show low selectivity for nitrogen species, poor control over sorbent activity, and incomplete separation of the specific compound classes. Nevertheless, it turned out that these procedures are time consuming and neither selective nor quantitative because some of the nitrogen compounds are only partially extracted or are lost during the extraction procedure due to matrix effects, thusly influencing the quality of the analytical response.

Currently, preparative and sample preparation techniques have been oriented to simplification, miniaturization, easy manipulation of the analytical devices, large reduction of toxic organic solvents, as well as small sample volume requirements in line with the principles of green analytical chemistry. For trace analysis in particular, the sorption-based methods have proved the best option enabling direct microextraction, mainly volatile and semi-volatile compounds, in almost all type of aqueous matrices.

Bar adsorptive microextraction $(\mathrm{BA} \mu \mathrm{E})$ was recently introduced[37] and offers to the operator the possibility to choose the most convenient sorbent phase (polymers or ACs), according to the chemical characteristics of the target analytes [36]. This analytical approach is an alternative by simplification, miniaturization and high-throughput to enhance selectivity and sensitivity, in particular for trace analysis. Furthermore, this new technique uses negligible amount of solvents and low sample volumes [36].This enrichment technique simultaneously combines microextraction and concentration of the analytes, operating under the floating sampling technology, in a one single step. On the other hand, reduces handling, the overall time required for sample preparation and is suitable to be combined with the high sensitivity of modern analytical instrumentation. Because all these reasons, $\mathrm{BA} \mu \mathrm{E}$ could be a good alternative to monitor traces of nitrogen compounds in commercial diesel.

\subsection{Application as novel sorbent phases for $\mathrm{BA} \mu \mathrm{E}$}

Production and improper disposal of agro-industrial waste from manufacturing processes are detrimental to sustainable development of natural resources and energy. Due to the amount of waste and harmful action on the environment, the fate of the waste originated in agro-industrial activities is a major concern of public managers, who seek a sustainable solution. The 
use of this waste is a desire not yet reached by Brazil, so it is necessary to search for alternatives to minimize this problem. Pyrolysis is an economical alternative to the use of agro-industrial waste to obtain products with higher added value. The production of biochar (pyrolysis carbonaceous residue) can be used as adsorbents source by minimizing the amount of waste released in the environment and consequently improving the environmental quality. In the process of pyrolysis of rice husk is generated a lot biochar for which it is necessary to use modern technology to reduce the volume, characterization, processing and utilization in order to add value and optimize the production process. The use of rice husk biochar as an alternative adsorbent is a possibility of proper disposal and environmentally friendly for this material. From the analytical point of view, the use of this material means a breakthrough in terms of methods of preparing samples absolutely environmental friendly.

Agro-industrial wastes have been used as precursors to prepare ACs and are getting more important due to their low costs, high apparent specific surface areas and good performance when tested as adsorbents for organic compounds. Recently, there is an increased emphasis on the topic of green chemistry, which is defined as the design of chemical products and processes that reduce or eliminate the use and generation of hazardous substances. The potentialities of rice husk ACs in the removal of nitrogen pollutants from diesel, an extremely complex matrix containing numerous organic constituents, in the case of the present study, was observed by microextraction technique involving the use of devices containing the produced alternative adsorbent and operated using the floating sampling technology [8] facilitating the identification, concentration and isolation of target compounds. The use of viable alternative systems which take into consideration the principles of Green Analytical Chemistry, using small amounts of organic solvents few steps and capacity extracting multiple samples simultaneously, is desirable to methods of preparing samples used in analytical chemistry.

The efficiency of $\mathrm{BA \mu E}$ can be substantially affected by the complexity of the matrices involved, since potential interferences with the actual matrix constituents may influence the yield of recovery. One way to minimize potential effects matrix is by using the standard addition method. This approach provides the level of accuracy required for trace analysis in a variety of systems. Another way to minimize the effects of matrix and co-elutions problems is the use of advanced analytical techniques such as $\mathrm{GC} \times \mathrm{GC}$, showing a significant increase in chromatographic resolution, which is crucial for the identification and quantification of analytes in complex mixtures.

To the best of our knowledge, a systematic study involving the production, characterization and application of selective bioadsorbent for analytical microextraction nitrogen compounds of interest in diesel using products derived from rice husk pyrolysis has not been reported before. In addition, the AC-RH may be used as a low-cost adsorbent, which is a kind of sorbent phase that offers many economic and environmental advantages compared to traditional sorbents. Furthermore, this approach is the first ever report of $\mathrm{BA} \mu \mathrm{E}$ applied in organic matrix and showed great ability to selectivity and sensitivity gain compared with conventional microextraction technique which was carried out in aqueous solution until the time.

\subsection{Detection and quantification of Carbazole in Diesel by BA $\mu \mathrm{E} / \mathrm{GC} \times \mathrm{GC}-\mathrm{qMS}$}

Nitrogen compounds in diesel fuel have typically been studied using GC with several specific detectors, including nitrogen and phosphorus (NPD) [35], nitrogen chemiluminescence (NCD) [53] and mass spectrometer (MS) [34] detectors. However, the complexity of diesel matrices and the limited peak capacity of GC columns appear, many times, as a drawback for the identification of nitrogen compounds during analytical separation, due to co-elution with interferences [35]. Consequently, unresolved peaks and low sensitivity are observed and a separation is required prior to the detection step for detailed molecular analysis of nitrogen compounds in diesel samples. Thus, the extraction and concentration of nitrogen compounds is either performed by liquid/liquid extraction (LLE) [51] or liquid/solid extraction (LSE) [53]. However, these procedures are time consuming and neither selective nor quantitative. Miniaturized analytical systems are effective alternatives for microextraction with little solvent consumption, reproductive, robust and reduced time.

One way to improve peak capacity of conventional separation techniques is to add another separation dimension. Therefore, comprehensive two-dimensional gas chromatography $(\mathrm{GC} \times \mathrm{GC})$ is a promising alternative to the limited resolution of conventional separation techniques. In $\mathrm{GC} \times \mathrm{GC}$, the entire sample is submitted to two online GC separations involving different properties of analytes. Two columns connected in series through a cryogenic modulator that traps, focuses and reinjects the effluent from the first column into the second one. The orthogonality of the separation is achieved by using columns of different selectivity, from data combining boiling point (related to the carbon atom number) and the polarity (related to the chemical structure) when using a classical combination of non-polar polar columns. Indeed, owing to a higher resolution power and an enhanced sensitivity [35], comprehensive two-dimensional gas chromatography offers unsurpassed possibilities for the characterization of nitrogen compounds in diesel. Several studies have employed GC $\times \mathrm{GC}$ for the analysis of nitrogen compounds using specific detectors[35, 50-52]. However, the use of one selective detector needs a preliminary 
and not exhaustive activity of assignment of the peaks on the basis on retention times of specific standard solutions or with the help of complementary analyses in the presence of mass spectrometer detector for analysis of the real sample. Regarding to the mass detectors, same studies have shown the consolidation of the fast quadrupole MS system for operation in the rapid scanning mode, allowing high data acquisition rates with values of up to $50 \mathrm{~Hz}[45,54-56]$. In order to solve the above problems, we developed a new method of the extraction and analysis using $\mathrm{BA} \mu \mathrm{E}$ and $\mathrm{GC} \times \mathrm{GC}$ coupled to a quadrupole mass spectrometer $(\mathrm{BA} \mu \mathrm{E} / \mathrm{GC} \times \mathrm{GC}-\mathrm{qMS})$ representing the state of the art organic chemical analysis of complex matrices.

In this contribution was produced, characterized and applied as adsorbent AC from the rice husk pyrolysis for analytical microextraction of carbazole in commercial diesel and the results were analyzed by GC $\times$ GC-qMS to check the applicability of this new method to extraction and to confirm its potential to quantitatively analyze diesel samples. Standard addition method was employed to reduce possible matrix interferences from the diesel sample. The diesel was fortified with carbazole standardto produce the corresponding spiking levels $\left(0.0125,0.025\right.$ and $\left.0.1 \mathrm{mg} \mathrm{L}^{-1}\right)$ of carbazole. Blank assays were also evaluated without spiking to ensure minimum or absence of matrix effects. The quantification (mgL ${ }^{-1}$ ) of carbazole was performed by measuring of the peak volume for fortified component in the $2 \mathrm{D}$ diagram and plotting the measured analytical signal against concentrations of the standard added. The unknown concentration of analyte in the sample was then determined by extrapolating the standard addition curve to the zero response value. Due to the low concentration of nitrogen compounds in diesel fuel sample, the quantification of carbazole is very difficult without the use of the standard addition method. Figure 6 shows the color diagram by GC $\times$ GC-qMS for the commercial diesel fortified, as can be seen in this figure the use of $\mathrm{GC} \times \mathrm{GC}$ allowed the separation of the carbazole from all the other compounds along the $\mathrm{y}$ axis. The problem of matrix effect was not observed for the real sample before standards addition, where the peak is more clearly identified. The average of data points per peak was 18 , which is an appropriate value for quantitative analyses, literature reference values were 15 to 20 data points [57].Results obtained showed good linearity, with $r^{2}$ higher than 0.9984and values of LOD and the LOQ were $0.45 \mu \mathrm{g} \mathrm{L}^{-1}$ and $1.37 \mu \mathrm{g} \mathrm{L}^{-1}$ respectively. Relative standard deviation (RSD) was less than $3.5 \%$ in the accuracy of analysis. For reproducibility, the RSD did not reach 6\%. Results obtained for the carbazole showed average recoveries of $91.0 \%$, which confirmed the great availability of the sites created from the chemical activation.

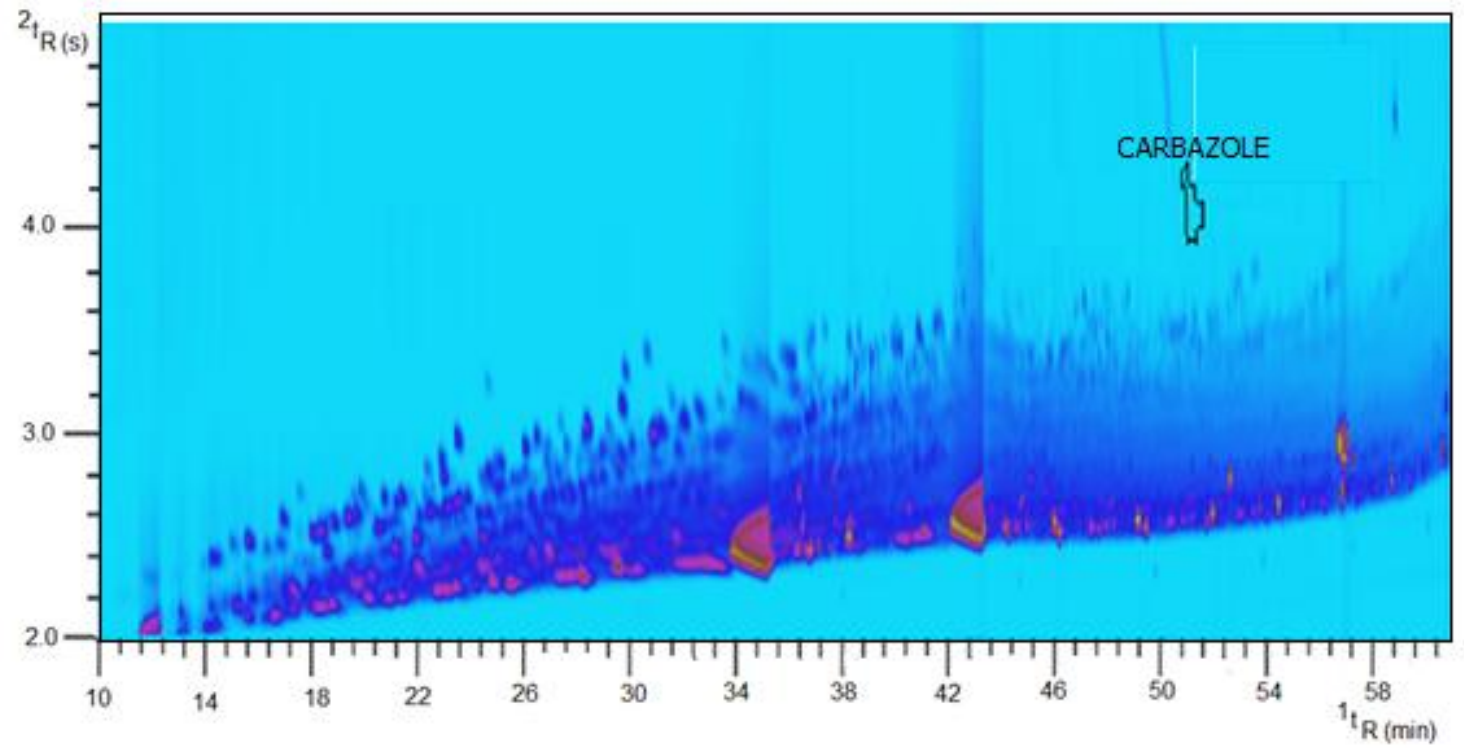

\section{FIGURE 6. EXAMPLE OF A TWO-DIMENSIONAL CHROMATOGRAM FROM A COMMERCIAL DIESEL SPIKED WITH CARBAZOLE (STANDARD ADDITION, $0.1 \mathrm{mg} \mathrm{L}^{-1}$ ), OBTAINED BY BA $\mu$ E/GC $\times G C-q M S$, UNDER STANDARD EXPERIMENTAL CONDITIONS.}

Therefore, the recovery results indicate that it is possible to add value to biochar from the rice husk pyrolysis to produce AC by chemical activation with $\mathrm{K}_{2} \mathrm{CO}_{3}$ preparing materials with appropriated characteristics to be used in carbazole removal in diesel oil. Whereas, neutral nitrogen species such as carbazoles, which are of low reactivity, tend to stay through the whole stage of deep hydrodesulfurization [58]. In general, the removal of nitrogen compounds from middle distillates by solid adsorbents (silica gel, alumina, AC, ion exchanged polymers) improves the reaction rate of the sulfur compounds through HDS process as stated by several authors [59-61]. 


\section{CONCLUSIONS}

Rice husk biochar may be converted into a cost-effective adsorbent to remove compounds with the use of chemical activation, being a good alternative to be used in adsorption-based technologies. Considering there is an urgent need to explore new applications of the rice husk, an important agro-industrial waste in South Brazil, and solve the environmental problems, both in relation to use of agricultural waste such as emissions of nitrogen from fuel, this study showed good answers to these challenges.

In the present study, a microextraction technique and a sensitive method using BA $\mu \mathrm{E}-\mathrm{LD} / \mathrm{GC} \times \mathrm{GC}$-qMS were applied for the first time for trace analysis of carbazole in diesel oil sample. The potential for the carbazole removal in diesel oil of low-cost ACs, obtained from rice husk pyrolysis and prepared by chemical activation was also investigated. Overall results indicate that it is possible to add value to thesebiochars. Besides the appearance of the micropores, which is generally promoted by the chemical activation, the present values of surface areas are much larger than those obtained after silica removal during the washings. Therefore, it is noteworthy that the results of this study point to the potential of producing high quality AC with surface area $1850 \mathrm{~m}^{2} \mathrm{~g}^{-1}$, with satisfactory adsorbent proprieties, using rice husk as starting material and $\mathrm{K}_{2} \mathrm{CO}_{3}$ as activating agent.

The sorbent tested demonstrated a good stability, robustness and microextraction efficiency. Furthermore, the enhanced peak capacity of comprehensive two-dimensional GC and the great identification capacity of mass spectrometry allow in the same analysis the accurate identification and quantification of carbazole. Therefore, this is a valid analytical technique with good selectivity and high sensitivity for the detection of compounds with very strong interference from the matrix.For the first time, a cost-effective and environmentally friendly method for extraction and detection of nitrogen compound in commercial diesel is reported.

\section{ACKNOWLEDGEMENTS}

The authors wish to thank CAPES and CNPq(Brazil; n401352/2014-5), as well as Fundação para a Ciência e a Tecnologia (Portugal; UID/MULTI/00612/2013, SFRH/BD/107892/2015) for financial support.

\section{REFERENCES}

[1] S. Nanda, A.K. Dalai, F. Berruti, J.A. Kozinski, "Biochar as an Exceptional Bioresource for Energy, Agronomy, Carbon Sequestration, Activated Carbon and Specialty Materials," Waste Biomass Valor, vol. 7, pp. 201-235, 2016.

[2] W. Kwapinski, C.M.P. Byrne, E. Kryachko, P. Wolfram, C. Adley, J. J. Leahy, E.H. Novotny, M.H.B. Haye, "Biochar from Biomass and Waste," Waste Biomass Valor, vol. 1, pp. 177-189, 2010.

[3] H. Deng, G.X. Li, H.B.Yang, J.P. Tang, J.Y. Tang, "Preparation of activated carbons from cotton stalk by microwave assisted KOH and $\mathrm{K}_{2} \mathrm{CO}_{3}$ activation," Chem. Eng. J., vol. 163, pp. 373-381, 2010.

[4] H. Deng, G.L. Zhang, X.L. Xu, G.H. Tao, J.L. Dai, "Optimization of preparation of activated carbon from cotton stalk by microwave assisted phosphoric acid chemical activation," J. Hazard. Mater., vol. 182, pp. 217-224, 2010.

[5] W. Li, L.B. Zhang, J.H. Peng, N. Li, X.Y. Zhu, "Preparation of high surface area activated carbons from tobacco stems with $\mathrm{K}_{2} \mathrm{CO}_{3}$ activation using microwave radiation," Ind. Crop. Prod., vol. 27, pp. 341-347, 2008.

[6] S.S. Lv, X.G. Chen, Y. Ye, S.H. Yin, J.P. Cheng, M.S. Xia, "Rice hull/ $\mathrm{MnFe}_{2} \mathrm{O}_{4}$ composite: preparation, characterization and its rapid microwave-assisted COD removal for organic wastewater," J. Hazard. Mater., vol. 171, pp. 634-639, 2009.

[7] A.S. Mestre, J. Pires, J.M.F. Nogueira, J.B. Parra, A.P. Carvalho, C.O. Ania, "Waste-derived activated carbons for removal of ibuprofen from solution: Role of surface chemistry and pore structure," Bioresour. Technol., vol. 100, pp. 1720-1726, 2009.

[8] Q.S. Liu, T. Zheng, P. Wang, L. Guo, "Preparation and characterization of activated carbon from bamboo by microwave-induced phosphoric acid activation," Ind. Crop. Prod., vol. 31, pp. 233-238, 2010.

[9] M. Auta, B.H. Hameed, "Preparation of waste tea activated carbon using potassium acetate as an activating agent for adsorption of Acid Blue 25 dye," Chem. Eng. J., vol. 171, pp. 502-509, 2011.

[10] E. Yagmur, M. Ozmak, Z. Aktas, "A novel method for production of activated carbon from waste tea by chemical activation with microwave energy," Fuel, vol. 87, pp. 3278-3285, 2008.

[11] K.B. Yang, J.H. Peng, C. Srinivasakannan, L.B. Zhang, H.Y. Xia, X.H. Duan, "Preparation of high surface area activated carbon from coconut shells using microwave heating," Bioresour. Technol., vol. 101, pp. 6163-6169, 2010.

[12] K.Y. Foo, B.H. Hameed, "Microwave-assisted preparation of oil palm fiber activated carbon for methylene blue adsorption," Chem. Eng. J., vol. 166, pp. 792-795, 2011.

[13] T.C. Chandra, M.M. Mirna, Y. Sudaryanto, S. Ismadji, "Adsorption of basic dye onto activated carbon prepared from durian shell: studies of adsorption equilibrium and kinetics," Chem. Eng. J., vol. 127, pp. 121-129, 2007.

[14] T.H. Wang, S.X. Tan, C.H. Liang, "Preparation and characterization of activated carbon from wood via microwave-induced $\mathrm{ZnCl2}$ activation," Carbon, vol. 47, pp. 1860-1883, 2009. 
[15] A.S. Mestre, C. Freire, J. Pires, A.P. Carvalho, M.L. Pinto, "High performance microspherical activated carbons for methane storage and landfill gas or biogas upgrade," J. Mater. Chem. A, vol. 2, pp. 15337-15344, 2014.

[16] A. Alvarez, G. Lopez, M. Amutio, J. Bilbao, M. Olazar, "Bio-oil production from rice husk fast pyrolysis in a conical spouted bed reactor," Fuel, vol. 128, pp. 162-169, 2014.

[17] C.H. Yun, Y.H. Park, G.H. Oh, C.R. Park, "Contribution of inorganic components in precursors to porosity evolution in biomassbased porous carbons," Carbon, vol. 41, pp. 2009-2012, 2003.

[18] D. An, Y. Guo, B. Zou, Y. Zhu, Z. Wang, "A study on the consecutive preparation of silica powders and active carbon from rice husk ash," Biomass Bioenergy, vol. 35, pp. 1227-1234, 2011.

[19] Y. Guo, S. Yang, K. Yu, J. Zhao, Z. Wang, H. Xu, "The preparation and mechanism studies of rice husk based porous carbon," Mater. Chem. Phys., vol. 74, pp. 320-323, 2002.

[20] S.A. Uzunova, I.M. Uzunov, S.V. Vassilev, A.K. Alexandrova, S.G. Staykov, D.B. Angelova, "Preparation of low-ash-content porous carbonaceous material from rice husks," Bulgarian Chem. Commun., vol. 42, pp. 130-137, 2010.

[21] Z. Yu, X. Meng, N. Liu, L. Shi, "A novel disposal approach of deactivated resin catalyst for methyl tert-butyl ether synthesis: Preparation of low-cost activated carbons with remarkable performance on dibenzothiophene adsorption," Fuel, vol. 207, pp. 47-55, 2017.

[22] T. Budinova, E. Ekinci, F. Yardim, A. Grimm, E. Björnbom, V. Minkova, M. Goranova, "Characterization and application of activated carbon produced by $\mathrm{H}_{3} \mathrm{PO}_{4}$ and water vapor activation," Fuel Process. Technol., vol. 87, pp. 899-905, 2006.

[23] X. Li, Y. Zuo, Y. Zhang, Y. Fu, Q. Guo, "In situ preparation of $\mathrm{K}_{2} \mathrm{CO}_{3}$ supported Kraft lignin activated carbon as solid base catalyst for biodiesel production," Fuel, vol. 113, pp. 435-442, 2013.

[24] D. Adinata, W.M.A. Wan Daud, M.K. Aroua, "Preparation and characterization of activated carbon from palm shell by chemical activation with $\mathrm{K}_{2} \mathrm{CO}_{3}$," Bioresour. Technol., vol. 98, pp. 145-149, 2007.

[25] M. Galhetas, A.S. Mestre, M.L. Pinto, I. Gulyurtlu, H. Lopes, A.P. Carvalho, "Chars from gasification of coal and pine activated with $\mathrm{K}_{2} \mathrm{CO}_{3}$ : Acetaminophen and caffeine adsorption from aqueous solutions," J. Colloid Interface Sci., vol. 433, pp. 94-103, 2014.

[26] K.Y. Foo, B.H. Hameed, "Utilization of rice husks as a feedstock for preparation of activated carbon by microwave induced KOH and $\mathrm{K}_{2} \mathrm{CO}_{3}$ activation," Bioresour. Technol., vol. 102, pp. 9814-9817, 2011.

[27] K.Y. Foo, B.H. Hameed, "Microwave-assisted preparation and adsorption performance of activated carbon from biodiesel industry solid reside: influence of operational parameters," Bioresour. Technol., vol. 103, pp. 398-404, 2012.

[28] K.Y. Foo, B.H. Hameed, "Preparation, characterization and evaluation of adsorptive properties of orange peel based activated carbon via microwave induced $\mathrm{K}_{2} \mathrm{CO}_{3}$ activation," Bioresour. Technol., vol. 104, pp. 679-686, 2012.

[29] I.I. Gurten, M. Ozmak, E. Yagmur, Z. Aktas, "Preparation and characterisation of activated carbon from waste tea using $\mathrm{K}_{2} \mathrm{CO}_{3}$," Biomass Bioenergy, vol. 37, pp. 78-81, 2012.

[30] A. Zhou, X. Ma, C. Song, "Liquid-phase adsorption of multi-ring thiophenic sulfur compounds on carbon materials with different surface properties," J. Phys. Chem. B, vol. 110, pp. 4699-4707, 2006.

[31] M. Almarri, X. Ma, C. Song, "Selective adsorption for removal of nitrogen compounds from liquid hydrocarbon streams over carbon- and alumina-based adsorbents," Ind. Eng. Chem. Res., vol. 48, pp. 951-960, 2009.

[32] M. Almarri, X. Ma, C. Song, "Role of surface oxygen-containing functional groups in liquid-phase adsorption of nitrogen compounds on carbon-based adsorbents," Energy Fuels, vol. 23, pp. 3940-3947, 2009.

[33] G.C. Laredo, J.A. De los Reyes, J.L. Cano, J.J. Castillo, "Inhibition effects of nitrogen compounds on the hydrodesulfurization of dibenzothiophene," Applied Catalysis A: General, vol. 207, pp. 103-112, 2001.

[34] E.C. Oliveira, M.C.C. Campos, A.S.A. Lopes, M.G.R. Vale, E.B. Caramão, "Ion-exchange resins in the isolation of nitrogen compounds from petroleum residues," J. Chromatogr. A, vol. 1027, pp. 171-177, 2004.

[35] C. von Mühlen, E.C. Oliveira, P.D. Morrison, C.A. Zini, E.B. Caramão, P.J. Marriott, "Qualitative and quantitative study of nitrogen-containing compounds in heavy gas oil using comprehensive two-dimensional gas chromatography with nitrogen phosphorus detection," J. Sep. Sci., vol. 30, pp. 3223-3232, 2007.

[36] J.M.F. Nogueira, "Stir-bar sorptive extraction - 15 years making sample preparation more environment friendly," Trend Anal Chem., vol. 71, pp. 214-223, 2015.

[37] N.R. Neng, A.R.M. Silva, J.M.F. Nogueira, "Adsorptive micro-extraction techniques-Novel analytical tools for trace levels of polar solutes in aqueous media," J Chromatogr. A, vol. 1217, pp. 7303-7310, 2010.

[38] S.M. Anisuzzaman, D. Krishnaiah, S. Abang, G.M. Labadin, "Adsorptive denitrogenation of fuel by oil palm shells as low cost absorbents," J. Applied Sciences, vol. 14, pp. 3156-3161, 2014.

[39] M.S.A. Moraes, F. Georges, S.R. Almeida, F.C. Damasceno, G.P.S. Maciel, C.A. Zini, R.A. Jacques, E.B. Caramão, "Analysis of products from pyrolysis of Brazilian sugar cane straw," Fuel Process. Technol., vol. 101, pp. 35-43, 2012.

[40] G. Horvàth, K. Kawazoe, "Method for the calculation of effective pore size distribution in molecular sieve carbon," J Chem En gineer Japan, vol. 16, pp. 470-475, 1983.

[41] J. Landers, G.Y. Gor, A.V. Neimark, "Density functional theory methods for characterization of porous materials," Colloids Surf. A, vol. 437, pp. 3-32, 2013.

[42] A.S. Mestre, J. Pires, J.M.F. Nogueira, A.P. Carvalho, "Activated carbons for the adsorption of ibuprofen," Carbon, vol. 45, pp. 1979-1988, 2007.

[43] N.R. Neng, A.S. Mestre, A.P. Carvalho, J.M.F. Nogueira, "Powdered activated carbons as effective phases for bar adsorptive microextraction $(\mathrm{BA} \mu \mathrm{E})$ to monitor levels of triazinic herbicides in environmental water matrices," Talanta, vol. 83, pp.1643-1649, 2011. 
[44] M. Thommes, K. Kaneko, A.V. Neimark, P.J. Olivier, F. Rodriguez-Reinoso, J. Rouquerol, K.S.W. Sing, "Physisorption of gases, with special reference to the evaluation of surface area and pore size distribution (IUPAC Technical Report)," Pure Appl. Chem., vol. 87, pp. 1051-1069, 2015.

[45] M. Adahchour, M. Brandt, H. Baier, R.J.J. Vreuls, A.M. Batenburg, U.A.T. Brinkman, "Cromprehensive two-dimensional gas chromatography coupled to a rapid-scanning quadrupole mass spectrometer: principles and applications," J. Chromatogr. A, vol. 1067, pp 245-254, 2005.

[46] F.C Wu, R.L Tseng, C.C Hu, "Comparisons of pore properties and adsorption performance of $\mathrm{KOH}$-activated and steam-activated carbons," Micropor. Mesopor. Mater, vol. 80, pp. 99-106, 2005.

[47] D. Dias,N. Lapa, M. Bernardo, D. Godinho, I. Fonseca, M. Miranda, F. Pinto, F. Lemos, "Properties of chars from the gasification and pyrolysis of rice waste streams towards their valorisation as adsorbent material," Waste Management, vol. 65, pp. 186-194, 2017.

[48] B-J. Skrifvars, P. Yrjas, J. Kinni, P. Siefen, M. Hupa, "The fouling behavior of rice husk ash in fluidized-bed combustion. 1. Fuel characteristics," Energy Fuel, vol. 19, pp. 1503-1511, 2005.

[49] L.L. Okumura, N.R. Stradiotto, "Simultaneous determination of neutral nitrogen compounds in gasoline and diesel by differential pulse voltammetry," Talanta, vol. 72, pp. 1106-1113, 2007.

[50] K.Lissitsyna, S. Huertas, L.C. Quintero, L.M. Polo, "Novel simple method for quantitation of nitrogen compounds in middle distillates using solid phase extraction and comprehensive two-dimensional gas chromatography," Fuel, vol. 104, pp.752-757, 2013.

[51] F. Adam, F. Bertoncini, N. Brodusch, E. Durand, D. Thièbaut, D. Espinat, M.C. Hennion, "New benchmark for basic and neutral nitrogen compounds speciation in middle distillates using comprehensive two-dimensional gas chromatography," J. Chromatogr. A, vol. 1148, pp. 55-64, 2007.

[52] F. Adam, F. Bertoncini, C. Dartiguelongue, K. Marchand, D. Thièbaut, M.C. Hennion, "Comprehensive two-dimensional gas chromatography for basic and neutral nitrogen speciation in middle distillates," Fuel, vol. 88, pp. 938-946, 2009.

[53] Y. Yongtan, "Determination of nitrogen compounds in catalytic diesel oil using gas chromatography," Chin J Chromatogr A, vol. 26, pp. 478-483, 2008.

[54] G. Purcaro, P.Q. Tranchida, C. Ragonese, L. Conte, P. Dugo, G. Dugo, L. Mondello, "Evaluation of a Rapid-Scanning Quadrupole Mass Spectrometer in an Apolar × Ionic-Liquid Comprehensive Two-Dimensional Gas Chromatography System," Anal. Chem., vol. 82, pp. 8583-8590, 2010.

[55] C. Cordero, C. Bicchi, D. Joulain, P. Rubiolo, "Identification, quantification and method validation for the analysis of suspected allergens in fragances by comprehensive two-dimensional gas chromatography coupled with quadrupole mass spectrometry and with flame ionization detection," J. Chromatogr. A, vol. 1150, pp. 37-49, 2007.

[56] P.Q. Tranchida, F.A Franchina, M. Zoccali, S. Panto, D. Sciarrone, P. Dugo, L. Mondello, "Untargeted and targeted comprehensive two-dimensional GC analysis using a novel unified high speed triple quadrupole mass," J. Chromatogr. A, vol. 1278, pp. 153-159, 2013.

[57] N. Dyson, "Peak distortion, data sampling errors and the integrator in the measurement of very narrow chromatographic peaks," $\mathrm{J}$ Chromatogr. A, vol. 842, pp. 321-340, 1999.

[58] A. Szymanska, M. Lewandowski, C. Sayag, G.D. Mariadassou, "Kinetic study of the hydrodenitrogenation of carbazole over bulk molybdenum carbide," J. Catal., vol. 218, pp. 24-31, 2003.

[59] H. Yang, J. Chen, C. Fairbridge, Y. Briker, Y. Jie Zhu, Z. Ring, "Inhibition of nitrogen compounds on the hydrodesulfurization of substituted dibenzothiophenes in light cycle oil," Fuel Process Technol, vol. 85, pp. 1415-1429, 2004.

[60] Y. Sano, K. Choi, Y. Korai, I. Mochida, "Adsorptive removal of sulfur and nitrogen species from a straight run gas oil over activated carbons for its deep HDS," Applied Catalysis B: Environmental, vol. 49, pp. 219-225, 2004.

[61] M. Sau, K. Basak, U. Manna, M. Santra, R.P. Verma, "Effects of organic nitrogen compounds on hydrotreating and hydrocracking reactions," Catalysis Today, vol. 109, pp. 112-119, 2005. 